\title{
Effect of photoperiod length on body mass and testicular growth in the house sparrow (Passer domesticus) and brahminy myna (Sturnus pagodarum)
}

\author{
Sanjay Kumar BHARDWAJ*, ANUSHI \\ Department of Zoology, Ch. Charan Singh University, Meerut-250 004, U. P. India
}

(Received 18 January 2005; accepted 1 September 2005)

\begin{abstract}
Two experiments studied the relative effects on body mass and testicular growth of stimulatory photoperiods applied simultaneously to two photosensitive species, the house sparrow (Passer domesticus) and brahminy myna (Sturnus pagodarum). Experiment 1 on the house sparrow consisted of two parts. In experiment 1A, beginning on 24 March 2002, short day pretreated sparrows were exposed for 12 weeks to 13L: 11D (13 h light: $11 \mathrm{~h}$ darkness), 20L: 4D and NDL (control). Experiment 1B was similar to 1A except that it used sparrows that were not treated with short days. This experiment was repeated at three different times in the year. Beginning on 29 December 2002 (for 24 weeks), 26 March 2003 (for 12 weeks) and 16 August 2003 (for 8 weeks), sparrows captured from the wild and acclimated to captive condition for 1 week were exposed to 13L: 11D and 20L: 4D. Each time, a group was maintained in NDL and served as the control. Experiment 2 was performed on myna and used an identical protocol. Beginning on 24 March 2002, myna that were captured from the wild and acclimated to captivity conditions were exposed for 16 weeks to 13L: 11D and 20L: 4D; a group was maintained in NDL and served as the control. There was photostimulation and subsequent regression of the testes on all day lengths except in the August group of experiment 1B. The effect on body mass was variable. Interestingly, however, the response to $20 \mathrm{~L}: 4 \mathrm{D}$ was relatively smaller as compared to $13 \mathrm{~L}: 11 \mathrm{D}$. Taken together, these results confirm that the two species use photoperiods in control of their reproductive cycle, and tend to indicate that exposure to unnatural long photoperiods may in fact be unfavorable and could compromise gonadal growth and development.
\end{abstract}

body mass / gonads / photoperiod length / Sturnus pagodarum / Passer domesticus

\section{INTRODUCTION}

Day length (= photoperiod) is used in the control of the timing of the annual reproductive cycle in almost all bird species living at high latitudes which have been investigated [1-7]. An initial assumption was that the photoperiod might not be an important factor in the regulation of the annual reproductive cycle of birds living at low-latitudes because of its smaller amplitude in variation over the year. However, the role of day length in the control of the annual reproductive cycle is clearly established in both subtropical and tropical species [8-17].

\footnotetext{
* Corresponding author: drskumar7@yahoo.com
} 
However, the photoperiod may not be singularly responsible for the regulation of all aspects of avian reproduction. Factors other than the environmental photoperiod, called supplementary factors, do influence photoperiod-induced effects on gonadal growth and development [18-20]. For example, Visser et al. [21] report that in great tits (Parus major) warmer temperature leads to mistiming of reproduction. Additionally, recent findings suggest that food availability can cause both direct and time-dependent effects on photoperiodic induction of testicular growth in the black headed bunting, Emberiza melanocephala [22] and house sparrow, Passer domesticus [23].

The role of factors that might negatively influence photoperiodism has not been examined. One interesting possibility is to examine if a photoperiodic stimulus, which serves as a primary cue in the regulation of avian reproduction, could exert negative effects if it is applied at an unusual strength. This has not been investigated. In the present study, we attempted to address this by examining the impact of a strong light stimulus on body mass and gonadal growth of two birds: the house sparrow (Passer domesticus) and brahminy myna (Sturnus pagodarum). Both species are photosensitive and use photoperiod in the regulation of their gonadal cycle [12, 13, 23, 24]. We subjected them simultaneously to a long day length corresponding to what these species experience in the wild and to an unusually long day length that these species never experience in the wild. It was hypothesized that the latter day length might negatively affect the photoperiodic response in these birds.

\section{MATERIALS AND METHODS}

We performed two experiments, one on the house sparrow (Passer domesticus; family - Ploceidae) and the other on brahminy myna (Sturnus pagodarum; family Sturnidae). They are seasonal with their reproductive season restricted to the spring and summer. Whereas sparrows breed in between March and May [17], the mynas' breeding season extends from March to August. The main reproductive periods can however vary with the population [25]. In the present study, the birds employed were caught locally at Meerut (latitude $29^{\circ} 01^{\prime}$; longitude $77^{\circ} 45^{\prime} \mathrm{E}$ ). At Meerut, seasonal variations in day length (sunrise to sunset) occur between $10 \mathrm{~h} 17 \mathrm{~min}$ (as on 22 December, shortest day length) and $14 \mathrm{~h} 01 \mathrm{~min}$ (as on 21 June, longest day length); this includes 24-28 min of morning and evening civil twilight periods. All birds employed in this study were adult males, which were acclimatized to captive conditions (NDL) before being exposed to the experimental conditions.

\subsection{Experiment 1: house sparrow (Passer domesticus)}

This experiment compared the response of sparrows under 13L: 11D (13 h light: $11 \mathrm{~h}$ darkness, a photoperiod which sparrows experience in the wild during later spring and early summer) with that under 20L: 4D (a photoperiod that sparrows never experience in the wild, hence unnatural). Birds held simultaneously under natural day lengths of $29^{\circ} \mathrm{N}$ served as the control. This experiment had two sub-experiments. In experiment $1 \mathrm{~A}$, beginning on 03 March 2002, we exposed three groups of sparrows ( $N=5$ or 6 per group) first to 8L: 16D for 3 weeks, and then subjected one group each to 13L: 11D, 20L: 4D or NDL for 12 weeks. Experiment 1B differed from experiment 1A in two ways: first it used sparrows that were acclimatized for 2 weeks in the outdoor aviary, and hence were untreated with short days prior to the experiment, and secondly the same experiment was repeated at three times in the year. Beginning on 29 December 2002 (part I), 26 March 2003 (part II) and 16 August 2003 (part III), a group of birds $(N=6)$ were subjected each to 13L: 11D, 20L: 4D and NDL. Part I ran for 24 weeks, part II for 12 weeks and part III for 8 weeks. 


\subsection{Experiment 2: brahminy myna (Sturnus pagodarum)}

This experiment on brahminy myna was done to understand if the results from house sparrows (experiment 1) were of general significance. Beginning on 24 March 2002, we exposed myna $(N=5$ or 6$)$ that were caught from the wild and acclimatized for 1 week in the outdoor aviary to 13L: 11D, 20L: 4D and NDL for a period of 16 weeks.

All birds were maintained on uniform husbandry conditions. The birds were housed in a group of 5 or 6 in wire-meshed cages $($ size $=60 \times 45 \times 45 \mathrm{~cm})$ placed inside the light-tight wooden photoperiodic chamber. Food and water were freely available to all groups. Whereas the sparrows were fed seeds of Pennisetum and Setaria, mynas were fed paste of flour from roasted gram. Artificial lighting was provided by 14 watt fluorescent tubes (CFL) at an intensity of $\sim 500$ lux at the perch level. The observations were recorded on changes in body mass and testis size at the beginning and at the end of the experiment, and at intervals during the experiment. Body mass was measured using a top pan balance to an accuracy of $0.1 \mathrm{~g}$. The testicular response was assessed by laparotomy under local anesthesia [22]. The dimensions of the left testis were recorded, and testis volume was calculated from $4 / 3 \pi a b^{2}$, where $a$ and $b$ denote half of the long and short axes, respectively.

The data are presented as means \pm SE. They were analyzed statistically using 1-way analysis of variance (ANOVA) with or without repeated measures, as appropriate, followed by a post-hoc Newman-Keuls test, if ANOVA indicated a significance of difference. The groups were also compared by 2-way ANOVA. A paired $t$-test was used to compare before and after treatment means of the same group. A comparison of two different groups at a single time-point was done using the Student $t$-test. Significance was taken at $P<0.05$.
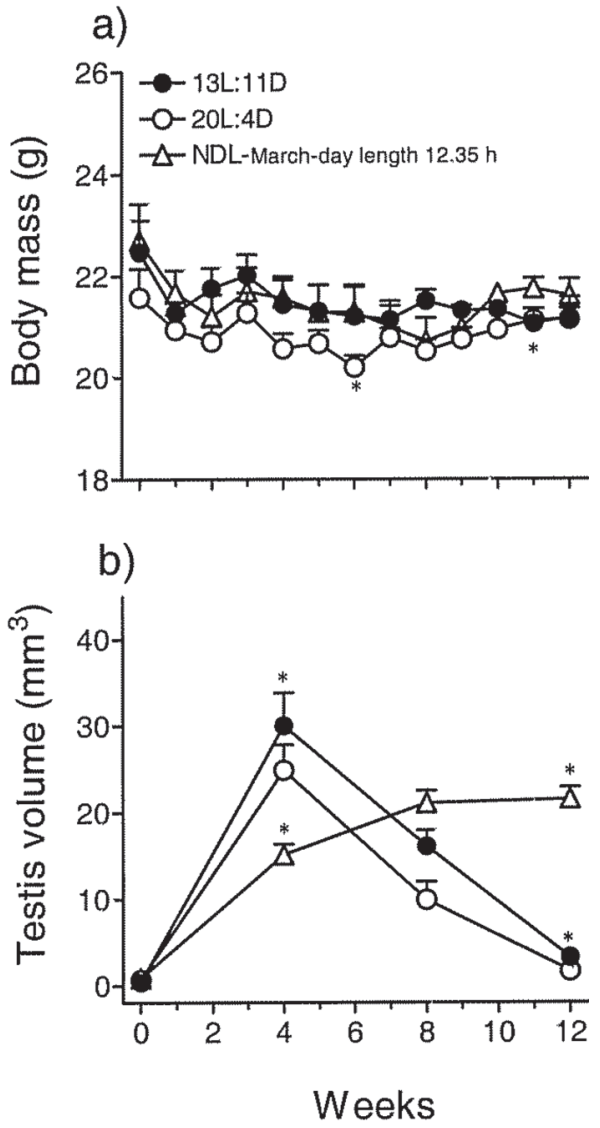

Figure 1. Mean ( \pm SEM) body mass $(\mathbf{a})$ and testis volume (b) of photosensitive male house sparrows $(n=6)$ exposed to 13L: 11D, 20L: 4D and NDL in the month of March (day length $12.35 \mathrm{~h}-14.11 \mathrm{~h}$ ). Body mass and testis size were recorded at weekly and 4-weekly intervals, respectively. Asterisks (*) on the symbol indicates the significance on difference at $P<0.05$.

\section{RESULTS}

\subsection{Experiment 1: house sparrow (Passer domesticus)}

The results from experiment $1 \mathrm{~A}$ are shown in Figure 1. There was a significant difference in body mass among the three groups $\left(\mathrm{F}_{2,195}=10.96, P<0.0001,2\right.$-way 
December

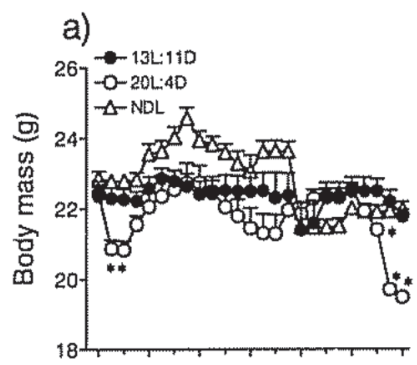

b)

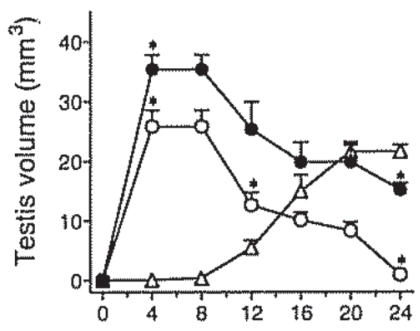

March

c)

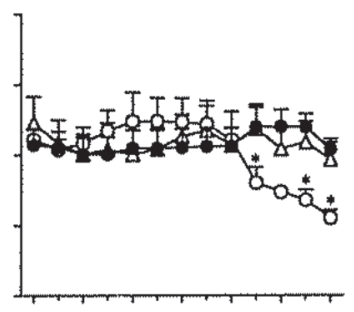

d)

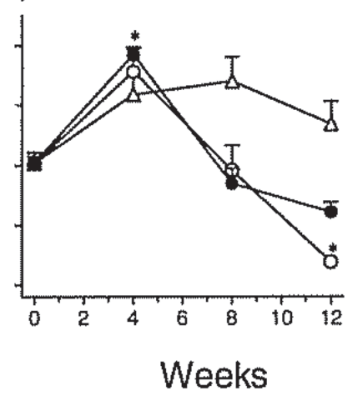

August

e)

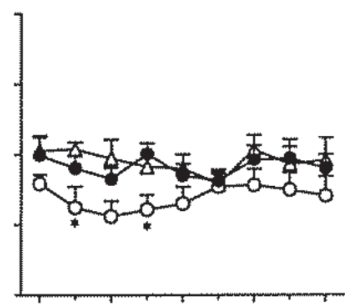

f)

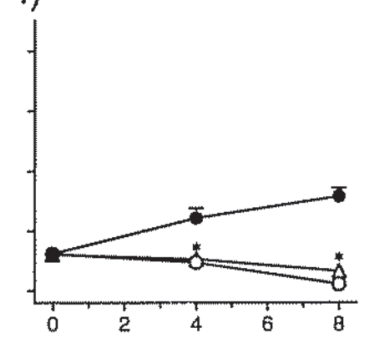

Figure 2. Mean (+ SEM) body mass $(\mathbf{a}, \mathbf{c}, \mathbf{e})$ and testis volume $(\mathbf{b}, \mathbf{d}, \mathbf{f})$ of male house sparrows $(n=6)$ exposed to 13L: 11D, 20L: 4D and NDL in the months of December (day length $10.40 \mathrm{~h}-$ $14.90 \mathrm{~h}$ ), March (day length $12.35 \mathrm{~h}-14.90 \mathrm{~h}$ ) and August (day length $13.32 \mathrm{~h}-11.40 \mathrm{~h}$ ). Body mass and testis size were recorded at weekly and 4-weekly intervals, respectively. Asterisks (*) on the symbol indicates the significance on difference at $P<0.05$.

ANOVA). The body mass of birds in NDL did not vary significantly $\left(\mathrm{F}_{12,60}=1.300\right.$, $P=0.2428$; 1-way RM ANOVA). However, there was a significant variation in body mass of birds under 13L:11D and 20L:4D (13L:11D: $\mathrm{F}_{12,60}=2.031, P=0.0367$; and 20L:4D: $\mathrm{F}_{12,60}=2.193, P=0.0234 ; 1-$ way RM ANOVA Fig. 1a). The testes were enlarged in all three groups after 4 weeks (13L:11D: $\mathrm{F}_{3,15}=35.17, P<0.0001$; 20L:4D: $\mathrm{F}_{3,15}=46.44, P<0.0001$; and NDL: $\mathrm{F}_{3,15}=76.17, P<0.0001 ; 1$-way RM ANOVA Fig. 1b). The birds showed a complete growth regression cycle under 13L:11D and 20L:4D, however, under NDL they were still growing and there was no regression until the end of the experiment.
The results (Fig. 2) of experiment 1B show that mean body mass among the three groups differed significantly during the course of the experiment only in December and August but not in March (December group; part I: $\mathrm{F}_{2,450}=53.57, P<0.0001$; August group; part III: $\mathrm{F}_{2,135}=12.28$, $P<0.0001$, and March group; part II: $\mathrm{F}_{2,195}=$ $1.095, P=0.3366,2$-way ANOVA). In general, birds under 20L:4D weighed less than those under 13L:11D and NDL.

In the December group (part I), the testes underwent growth and regression under 13L:11D and 20L:4D (13L:11D: $\mathrm{F}_{6,36}=$ 21.17, $P<0.0001$; and 20L:4D: $\mathrm{F}_{6,36}=$ 44.22, $P<0.0001$; 1-way RM ANOVA). The birds had fully stimulated testes after 
4 weeks of exposure, however, the testicular regression was faster in 20L:4D birds as compared to $13 \mathrm{~L}: 11 \mathrm{D},(P<0.05$; paired $t$-test) and so was the magnitude of response. On the contrary, the NDL group remained unstimulated until 8 weeks; there was initiation of response after 12 weeks of exposure and the testes continued growing until the end of the experiment. At the time of the experiment, March (part II) birds had already grown testes, though up to halfmaximum. When they were transferred to similar photoperiods there was a further increase in testis volume in 13L:11D and 20L:4D (13L:11D: $\mathrm{F}_{3,15}=49.75, P<0.0001$; and 20L:4D: $\mathrm{F}_{3,15}=28.60, P<0.0001$; 1-way RM ANOVA) after 4 weeks and subsequently, the testes started regressing after 8 weeks of exposure. The testes regression in 20L:4D of the March group was faster than 13L:11D by 12 weeks, similarly to December birds $(P<0.001$; unpaired $t$-test $)$. The testes in the NDL group showed growth of the testes and this was maintained until the end of the experiment. The testis in August birds (part III) had already undergone regression at the time of the experiment. Exposure to 20L:4D and NDL led to further regression, however birds under 13L:11D showed stimulation of the testis (13L:11D: $\mathrm{F}_{2,10}=26.02, P=0.0001$; and 20L:4D: $F_{2,10}=38.84, P<0.0001$; NDL: $\mathrm{F}_{2,10}=11.77, P=0.0024$; 1-way RM ANOVA).

\subsection{Experiment 2: brahminy myna (Sturnus pagodarum)}

The results are shown in Figure 3a. There was significant variation in body mass of birds exposed to $13 \mathrm{~L}$ : $11 \mathrm{D}\left(\mathrm{F}_{16,67}=2.398\right.$, $P=0.01$; 1 -way RM ANOVA) and 20L: 4D $\left(\mathrm{F}_{16,67}=6.112, P<0.0001 ; 1\right.$-way RM ANOVA) (Fig. 3a). Under NDL also, a change in body mass over the experimental period was close to statistical significance $\left(\mathrm{F}_{16,67}=1.833, P=0.0519\right.$; 1-way $\mathrm{RM}$ ANOVA). However, there was no group difference in body mass of the three groups $\left(\mathrm{F}_{2,153}=0.1317, P>0.05 ; 2\right.$-way ANOVA $)$.

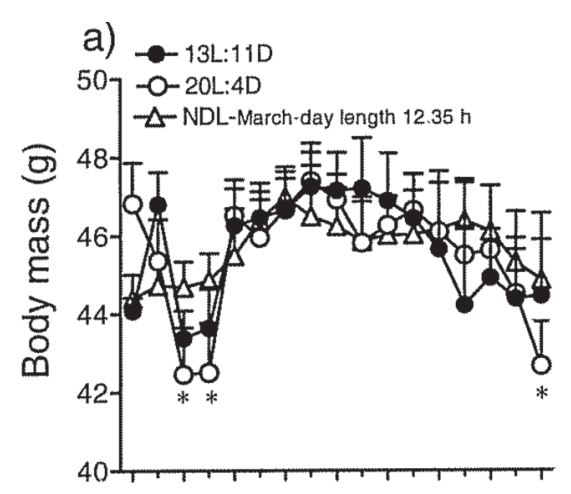

b)

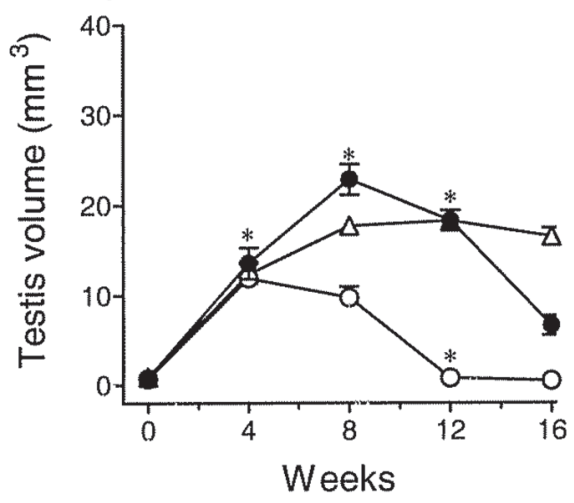

Figure 3. Mean ( \pm SEM) body mass (a) and testis volume $(\mathbf{b})$ of male brahminy myna $(n=6)$ exposed to 13L: 11D, 20L: 4D and NDL in the month of March (day length $12.35 \mathrm{~h}-14.11 \mathrm{~h}$ ). Body mass and testis size were recorded at weekly and 4-weekly intervals, respectively. Asterisks $(*)$ on the symbol indicates the significance on difference at $P<0.05$.

Testes were stimulated in all groups, but were significantly smaller in 20L birds $\left(\mathrm{F}_{2,45}=100.7, P<0.0001 ; 2\right.$-way ANOVA). However, testicular regression in 20L birds occurred relatively earlier and the regression curve was steeper compared to the other two groups (cf. Fig. 3b). As with sparrows, 13L: 11D induced significantly larger $(P<0.001$, Student Newman-Keuls test $)$ testicular response in the birds. In this study however, the response of birds under NDL was similar to that under 13L: 11D. 


\section{DISCUSSION}

Both sparrows and myna underwent testicular growth and regression when exposed to stimulatory photoperiods in all the experiments except in part III of experiment $1 \mathrm{~B}$ in which the testes were stimulated to sub-maximal size (13L group) or were slightly stimulated (20L and NDL groups). Since this particular experiment (part III, experiment 1B) had begun on 16 August, it is likely that birds at this time had not fully recovered from the photorefractoriness. It is known that sparrows undergo a period of refractoriness following reproduction during which they are apparently unresponsive to stimulatory effects of light [26, 27]. The present results hence confirm the results from several previous investigations [12, 13, 17, 28-31] suggesting that the house sparrow and brahminy myna are photoperiodic species. When exposed to stimulatory photoperiods, they undergo gonadal growth and regression. In a recent study on brahminy myna [32], we have reported that body mass and testes have a different profile of photoperiodic response with two different threshold photoperiods for dissipation of the post-reproductive refractoriness. In the present experiments, however, body mass was not increased as a result of exposure to stimulatory photoperiods.

There are a number of species that have been investigated to understand the photoperiodic control of annual reproductive cycle in birds. A most consistent view that has emerged from these investigations is summarized as follows. When exposed to stimulatory photoperiods, the longer the photophase, the faster is the testicular response and the earlier the regression and onset of photorefractoriness [5, 33, 34]. It is also suggested that a longer photophase leads to rapid and greater photoperiodic induction. In a study on Japanese quail (Coturnix c. japonica), Follett and Maung [35] found that the rate of testicular growth was slower by $50 \%$ in birds exposed to 12L:12D compared to 14 or longer light hours per day; a near full testicular growth occurred in 13L:11D. This is true of both male and female birds. There was a rapid gonadal growth and more rapid onset of photorefractoriness in both male and female European starlings, Sturnus vulgaris [36]. Morton et al. [37] showed that a longer photophase led to a more rapid ovarian growth and more rapid subsequent ovarian decline in the white-crowned sparrow (Zonotrichia leucophrys gambelii). In the European starling (Sturnus vulgaris) photoperiodic induction is reported to also be dependent on light intensity: a long photoperiod applied at a low light intensity results in photoperiodic induction comparable to that produced by a relatively a shorter photoperiod [38]. Our results are also comparable to those reported on Indian resident species, viz. the Indian weaver bird, Ploceus philippinus [9], yellow throated sparrow, Gymnorhis xanthocollis [39] and Common Indian myna, Acridotheres tristis [40].

However, the observation that was inconsistent with the above findings was of more interest. Compared to $13 \mathrm{~L}, 20 \mathrm{~L}$ induced more rapid photorefractoriness (Figs. 2b, 2d, 3b), as one would expect (see above), but did not lead to more rapid gonadal growth (cf. Figs. 1-3). Any argument that we missed the peak gonadal response under 20L:4D if it occurred between 0 and 4 weeks is weak since growth and subsequent regression do not usually occur within 4 weeks in several species investigated $[10,41]$. We intend nonetheless to make a comparative study with greater frequency of observations in future sets of experiments. In the present study, however, there was a difference in the photoperiodic induction between two long photoperiods, 13L:11D and 20L:4D. The response under 13L:11D, which was closer to what day length sparrows and brahminy myna experience at this latitude $\left(29^{\circ} \mathrm{N}, 77^{\circ} \mathrm{E}\right)$, was greater than that under $20 \mathrm{~L}: 4 \mathrm{D}$ that these birds never experience in the wild. It could be that the exposure to $20 \mathrm{~h}$ light each day consecutively for several weeks compromises the activity of the hypothalamohypophyseal-gonadal system leading to an 
attenuated response in body mass and testes. It is reported that exposure of continuous light (LL) causes high mortality in starlings [42]. When a stimulatory photoperiod is applied at high light intensity, the blackheaded bunting exhibits an attenuated photoperiodic induction [24]. Is it then that an unnatural light stimulus could become stressful? There is evidence that unnatural situations can lead to chronic and deleterious effects on bird physiology seen on the suppression of gonadal activities, immune system, growth and severe protein losses [43-45]. If the attenuated response under $20 \mathrm{~L}$ is due to the fact that this is an unnatural photophase to birds since they are never exposed to it in their wild condition, this might help explain the difference usually found in the photoperiodic strategy between populations at different latitudes.

\section{ACKNOWLEDGEMENTS}

Financial support from the Council of Scientific and Industrial Research, New Delhi through a research project $(37(1074) / 01-E M R-I I)$ to SKB is acknowledged. We also thank both the anonymous reviewers for their helpful comments and criticism on improving the draft of the manuscript.

\section{REFERENCES}

[1] Farner DS, Follett BK. Light and other environmental factors affecting avian reproduction. J Anim Sci 1966, 25: 90-118.

[2] Murton RK, Westwood NJ. Avian Breeding Cycles, Oxford University Press, Clarendon, London, 1977, p 594.

[3] Follett BK. Birds. In: Lamming GE(Ed), Marshall's Physiology of Reproduction, Churchill Livingstone, Edinburgh, UK, 1984, p 283.

[4] Hahn TP. Integration of photoperiodic and food cues to time changes in reproductive physiology by an opportunistic breeder, the red cross bill, Loxia curvirostra (Aves: Carduelinae). J Exp Zool 1995, 272: 213-226.

[5] Kumar V. Photoperiodism in higher vertebrates: An adaptive strategy in temporal environment. Indian J Exp Biol 1997, 35: 427-437.
[6] Dawson A, King VM, Bentley GE, Ball GF. Photoperiodic control of seasonality in birds. J Biol Rhythms 2001,16: 133-176.

[7] Deviche P, Small T. Photoperiodic control of seasonal reproduction: neuroendocrine mechanisms and adaptations. In: Dawson A, Chaturvedi CM (Eds), Avian Endocrinology, Narosa Publishing House, New Delhi, 2001, p 113-128.

[8] Thapliyal JP, Tewary PD. Effect of light on pituitary, gonad and plumage pigmentation in the Avandavat, Estrilda amandava and baya weaver, Ploceus philippinus. Proc Zool Soc (London) 1964, 142: 67-71.

[9] Singh S, Chandola A. Photoperiodic control of seasonal reproduction in tropical weaver bird. J Exp Zool 1981, 216: 293-298.

[10] Tewary PD, Kumar V, Prasad BN. Influence of photoperiod in subtropical migratory finch, the common Indian rose finch, Carpodacus erythrinus. Ibis 1983, 125: 115-120.

[11] Tewary PD, Dixit AS. Photoperiodic regulation of the reproduction in the subtropical yellow-throated sparrows, Gymnorhis xanthocollis. Condor 1986, 88: 70-73.

[12] Kumar BS, Kumar V. Seasonal reproduction in subtropical brahminy myna, Sturnus pagodarum: Role of photoperiod. Gen Comp Endocrinol 1991, 83: 354-365.

[13] Kumar BS, Kumar V. Photoperiodic control of annual reproductive cycle in subtropical brahminy myna, Sturnus pagodarum. Gen Comp Endocrinol 1993, 89: 149-160.

[14] Gwinner E, Scheuerlein A. Seasonal changes in day-light intensity as a potential zeitgebers of circannual rhythms in equatorial stonechats. J Ornithol 1998, 139: 407-412.

[15] Hau M, Wikelski M, Wingfield JC. A neotropical bird can measure changes in tropical photoperiod. Proc R Soc Lond B 1998, 265: 8995.

[16] Hau M. Timing of breeding in variable environments: Tropical birds as model systems. Horm Behav 2001, 40: 281-290.

[17] Trivedi A. Seasonal responses of house sparrow (Passer domesticus) Linneaus at $27^{\circ} \mathrm{N}$. $\mathrm{PhD}$ dissertation, Lucknow University, Lucknow, 2005.

[18] Wingfield JC, Farner DS. The reproductive endocrinology of wild species. In: Farner DS, King JR, Parkes KC (Eds), Avian Biology, Vol IX, Academic Press, New York 1993, p 163.

[19] Burmeister S, Wilczynski W. Social signals influence hormones independently of calling behavior in the tree frog (Hyla cinerea). Horm Behav 2000, 38: 201-209. 
[20] Mistlberger RE, Skene DJ. Social influences on mammalian circadian rhythms: animal and human studies. Biol Rev 2004, 79: 533-556.

[21] Visser ME, van Noordwijk AJ, Tinbergen JM, Lessells CM. Warmer springs lead to mistimed reproduction in great tits (Parus major). Proc R Soc Lond B 1998, 265: 1867-1870.

[22] Kumar V, Singh S, Misra M, Malik S. Effects of duration and time of food availability on photoperiodic responses in the migratory male black headed bunting (Emberiza melanocephala). J Exp Biol 2001, 204: 2843 2848.

[23] Bhardwaj SK, Anushi. Effect of duration and time of food availability on photoperiodic response in the male house sparrow, Passer domesticus. Reprod Nutr Dev 2004, 44: 29-35.

[24] Misra M, Rani S, Singh S, Kumar V. Regulation of seasonality in the migratory male black headed bunting (Emberiza melanocephala). Reprod Nutr Dev 2004, 44: 341352.

[25] Ali S, Ripley SD. Handbook of birds of Indian and Pakistan, Vol. 5, Oxford University Press, Bombay, London, New York, 1972, p 160.

[26] Ravi Kumar G, Tewary PD. Photorefractoriness and its termination in the subtropical house sparrow, Passer domesticus: involvement of circadian rhythm. Chronobiol Int 1990, 7: 187-191.

[27] Hahn TP, Ball GF. Changes in brain GnRH associated with photorefractoriness in house sparrows (Passer domesticus). Gen Comp Endocrinol 1995, 99: 349-363.

[28] Menaker M. Rhythm, reproduction and photoreception. Biol Reprod 1971, 4: 295-308.

[29] Prasad BN. Photoperiodic control of reproduction in some Indian Birds. PhD dissertation, Banaras Hindu University, Varanasi, India, 1980.

[30] Dawson A. Photoperiodic control of testicular regression and moult in male house sparrows, Passer domesticus. Ibis 1991, 133: 312-316.

[31] Dawson A. Photoperiodic control of the termination of breeding and the induction of moult in house sparrows, Passer domesticus. Ibis 1998, 140: 35-40.

[32] Bhardwaj SK, Kumar P. Photosensitivity in body mass and testicular activity of brahminy myna, Sturnus pagodarum. Reprod Nutr Dev 2004, 44: 365-369.

[33] Farner DS, Follett BK. Reproductive periodicity in bird. In: Barrington JW (Ed), Hor- mones and Evolution, Academic Press, London, 1979, p 829.

[34] Nicholls TJ, Goldsmith AR, Dawson A. Photorefractoriness in birds and comparison with mammals. Physiol Rev 1988, 68: 133-176.

[35] Follett BK, Maung SL. Rate of testicular maturation, in relation to gonadotrophin and testosterone levels, in quail exposed to various artificial photoperiods and to natural day lengths. J Endocrinol 1978, 78: 267-280.

[36] Dawson A, Goldsmith AR. Plasma prolactin and gonadotrophins during gonadal development and the onset of photorefractoriness in male and female starlings (Sturnus vulgaris) on artificial photoperiods. J Endocrinol 1983, 97: 253-260.

[37] Morton ML, Pereyra ME, Baptista LF. Photoperiodically induced ovarian growth in the white crowned sparrow (Zonotrichia leucophrys gambelii) and its augmentation by song. Biochem Physiol A 1985, 80: 93-97.

[38] Bentley GE, Goldsmith AR, Dawson A, Briggs $C$, Pemberton $M$. Decreased light intensity alters the perception of day length by male European starlings (Sturnus vulgaris). J Biol Rhythms 1998, 13: 140-150.

[39] Tewary PD, Tripathi PM, Tripathi BK. Effects of exogenous gonadal steroids and castration of photoperiodic responses of the yellow-throated sparrow. Indian J Exp Biol 1985, 23: 426-428.

[40] Chaturvedi CM, Thapliyal JP. Thyroidectomy and gonadal development in common myna (Acridotheres tristis). Gen Comp Endocrinol 1979, 39: 327-329.

[41] Kumar V, Tewary PD. Response to experimental photoperiods by a migratory bunting, Emberiza melanocephala. Ibis 1983, 125: 305-312.

[42] Rutledge JT, Schwab RG. Testicular metamorphosis and prolongation of spermatogenesis in starlings (Sturnus vulgaris) in the absence of daily photostimulation. J Exp Zool 1974, 187: 71-76.

[43] Axelord J, Reisinie TD. Stress hormones: Their interaction and regulation. Science 1984, 224: 452-459.

[44] Sapolsky H. Stress, social status and reproductive physiology in free-living baboons. In: Crews D (Ed), Psychobiology of reproductive behaviour: an evolutionary perspective, Prentice hall, Englewood Cliffs, New Jersey, 1989, p 291.

[45] Manser RL. The assessment of stress in laboratory animals. RSPCA, Sussex, 1992. 